\title{
Relações de cooperação para competitividade $e$ inovação no APL de TI do Vale do Rio Pardo (RS)
}

\author{
Rejane Maria Alievi ${ }^{1}$ \\ Ingridi Vargas Bortolaso ${ }^{2}$ \\ Pietro Cunha Dolci ${ }^{3}$ \\ Eduardo Kroth ${ }^{4}$ \\ Viviane Ceratti Leseux ${ }^{5}$
}

\begin{abstract}
Resumo: As abordagens sobre arranjos produtivos locais, como forma de dinamizar e explicar o dinamismo de determinados espaços geográficos, são a base do estudo sobre o Arranjo Produtivo Local (APL) da Tecnologia da Informação (TI) da Região do Vale do Rio Pardo (RS). O objetivo central foi verificar se as questões relativas à proximidade geográfica do aglomerado produtivo permitem que as relações de cooperação ocorram com maior intensidade e sejam fatores de competitividade e inovação de um arranjo produtivo local. Para alcançar o objetivo, foi realizada uma pesquisa qualitativa exploratória com empresas do APL de TI, via entrevistas semiestruturadas. Os resultados indicam que a proximidade geográfica é um fator competitivo, a partir da cooperação entre as empresas do APL e também com outros atores, como Universidade, Associações e Governo, gerando externalidades positivas para o conjunto de empresas. Essas inovações foram identificadas como oriundas de pesquisas de mercado, desenvolvimento interno e qualificação da equipe. Assim, a partir desse estudo, evidenciouse como as empresas do APL de TI do Vale do Rio Pardo têm realizado atividades em conjunto em relação a suas competitividades individuais e coletivas para a criação de ambientes inovadores.
\end{abstract}

Palavras-chave: Arranjo Produtivo Local. Cooperação. Empresas de TI. Vale do Rio Pardo.

Abstract: The approaches to local productive arrangements, as a way of dynamizing and explaining the dynamism of certain geographic spaces, are the basis of the study on the Local Productive Arrangements (LPA) of Information Technology (IT) of the Rio Pardo Valley. The main objective was to verify if the issues related to the geographic proximity of the LPA allow cooperation relationships to create competitiveness and innovation of a local productive arrangement. In order to achieve the objective, a qualitative exploratory research was carried out with IT companies from LPA through semi-structured interviews. The results indicate that the geographical proximity is a competitive factor based on the cooperation between LPA companies and also with other actors, such as University, Associations and Government, generating positive externalities for all companies. These innovations were identified as coming from market research, internal development and team qualification. Thus, from this study it was

${ }^{1}$ Doutora em Administração pela Universidade Federal do Rio Grande do Sul (UFRGS) e professora do Programa de Pós-Graduação em Administração da Universidade de Santa Cruz do Sul (UNISC). ralievi@unisc.br.

${ }^{2}$ Doutora em Administração pela Universidade do Vale do Rio dos Sinos (UNISINOS) e professora do Programa de Pós-Graduação em Administração da Universidade de Santa Cruz do Sul (UNISC). ingridibortolaso@unisc.br.

${ }^{3}$ Doutor em Administração pela Universidade Federal do Rio Grande do Sul (UFRGS) e coordenador do Programa de Pós-Graduação em Administração da Universidade de Santa Cruz do Sul (UNISC). pcdolci@unisc.br.

${ }^{4}$ Mestre em Computação pela Universidade Federal do Rio Grande do Sul (UFRGS) e professor do Departamento de Computação da Universidade de Santa Cruz do Sul (UNISC). kroth@unisc.br.

${ }^{5}$ Mestranda do Programa de Pós-Graduação em Administração da Universidade de Santa Cruz do Sul (UNISC). Bolsista BIPPS/UNISC. viviane.leseux@gmail.com.

COLÓQUIO - Revista do Desenvolvimento Regional - Faccat - Taquara/RS - v. 16, n. 1, jan./jun. 2019 
evidenced how the IT companies of LPA of Rio Pardo Valley have carried out joint activities in relation to their individual and collective competitivities for the creation of innovative environments.

Keywords: Local Productive Arrangements. Cooperation. IT Companies. Rio Pardo Valley

\section{Introdução}

O contexto contemporâneo exige das organizações capacidades dinâmicas específicas, com maior ênfase na capacidade adaptativa, novas formas de competição e de difenciação. Neste contexto, as tecnologias de informação (TIs) têm se tornado cada vez mais um fator determinante para as organizações, à medida que a agilidade com que as informações são processadas representa um dos diferenciais de competição e amplia as chances de sua sobrevivência no mercado. Verifica-se, na literatura recente, uma convergência de visões entre as diversas escolas do pensamento na busca de um melhor entendimento sobre os fatores subjacentes ao melhor desempenho competitivo das empresas. O foco de análise deve estar centrado não apenas na empresa individual, mas, principalmente, na investigação das relações entre as firmas e entre estas e as demais instituições em um espaço geograficamente delimitado.

Na literatura, elementos de análise sobre aglomerações produtivas estão sendo tratados como locus central de dinamismo tecnológico e competitividade. A proximidade geográfica tende a ser vista como o melhor contexto para facilitar a troca de conhecimento entre as empresas. Esse foco de análise, a redescoberta do conceito e importância das aglomerações produtivas e inovadoras, passou a ser estudado com mais ênfase a partir do início de 1990. Nos últimos anos, esses estudos se intensificaram na análise dos APL entre empresas de TI (BALDISERA; CERETTA; REIS, 2017; ROCHA et al., 2018; SOTELLO et al., 2018) devido à importância e destaque que têm recebido, tanto da academia quanto da prática.

Partindo desse contexto, o objetivo central foi verificar se as questões relativas à proximidade geográfica do aglomerado produtivo permitem que as relações de cooperação ocorram com maior intensidade e sejam fatores de competitividade e inovação de um arranjo 
produtivo local. Para responder aos questionamentos, definiu-se como objeto empírico de pesquisa o Arranjo Produtivo Local da Região do Vale do Rio Pardo, do estado do Rio Grande do Sul.

O estudo justifica-se pela importância do APL de TI na Região do Vale do Rio Pardo e pela carência de estudos analisando as relações de cooperação e de fontes de informação em empresas na região. Além disso, o Governo do Estado do Rio Grande do Sul, por meio da Agência Gaúcha de Desenvolvimento e Promoção do Investimento, reconheceu oficialmente o Arranjo Produtivo Local (APL) da Teconologia e Informação do Vale do Rio Pardo, em agosto de 2017. A iniciativa de fomentar o desenvolvimento do APL, ação essa protagonizada pelo governo estadual do RS, está vinculada ao reconhecimento de que as políticas de fomento ao desenvolvimento de grupos empresas são mais efetivas do que quando direcionadas às empresas que operam individualmente. Alguns autores destacam que a força competitiva das empresas que atuam coletivamente está diretamente vinculada a cooperação desenvolvida entre empresas (BRASIL, 2004; CASTRO; GONÇALVES, 2014). No entanto, é sabido que o apoio governamental deve estimular a estruturação e a perenidade. Neste sentido, o desenvolvimento de ações de parcerias com universidades e instituições de pesquisa é fundamental para o desenvolvimento local/nacional.

O artigo está estruturado da seguinte forma: inicialmente, apresenta-se o referencial teórico sobre os principais estudos e autores relativos a arranjos produtivos locais de inovação. A seguir, são descritos os procedimentos metodológicos adotados para o desenvolvimento do estudo. Após, são apresentados os resultados da pesquisa empírica realizada junto às empresas do APL de TI. Por fim, o estudo apresenta as considerações finais, destacando os resultados mais relevantes que nortearam o desenvolvimento da pesquisa.

\section{Referencial teórico}

Nos últimos anos, é crescente o interesse da economia pela dimensão espacial do crescimento econômico. As mudanças nos processos produtivos globais, em diferentes 
territórios, provocaram revisões nas teorias e geraram a necessidade de novas políticas de desenvolvimento. Com os desequilíbrios regionais-locais, intensificados pela reorganização da produção globalizada, cresceu a importância da produção flexível, da inovação e das vantagens competitivas. As mudanças verificadas nas economias capitalistas a partir do início dos anos 1970, provocadas pelo esgotamento do modelo fordista de acumulação e crescimento, também provocaram reações dos governos para amenizar as consequências negativas desse esgotamento. Estes passaram a utilizar os instrumentos do Estado para atuar na organização da produção e na regulação da economia. Em termos de organização produtiva, um desses instrumentos é a reformulação dos padrões tradicionais de localização das empresas através da descentralização, incentivando a realização de pesquisas científicas que na área de arranjos produtivos locais (APLs) e Governança.

De acordo com Lastres e Cassiolato (2003, p. 3), os APLs podem ser entendidos como "aglomeração territorial de atores econômicos, políticos e sociais com foco em um conjunto específico de atividades econômicas que apresentam vínculos mesmo que incipientes". Complementarmente, o APL como forma de arranjo colaborativo interorganizacional, de maneira mais geral, é uma expressão utilizada com o objetivo de "representar uma forma de organização industrial cuja estrutura é constituída por um aglomerado de empresas - de um modo geral de pequeno e médio porte - localizadas territorialmente e relacionadas entre si por uma miúda divisão do trabalho" (COSTA; COSTA, 2007, p. 56). Lastres e Cassiolato (2003), informam que o APL é um conjunto de empresas que mantêm vínculos tangíveis e intangíveis entre si, fracos ou intensos, configurando-se em aglomerações espaciais.

Visto dessa maneira, tanto no cenário internacional como no nacional, cresce o interesse pelos APLs como formas de configurações interorganizacionais hábeis para estimular o desenvolvimento local, uma vez que os APLs como uma forma de arranjo colaborativo interorganizacional, ao trabalharem em relações de cooperação, produzem ganhos diversificados aos envolvidos, aumentando as forças competitivas dos envolvidos. Nessa lógica, o interesse de pesquisa sobre APLs ou outras formas de aglomerações produtivas, vistas como alternativas para o desenvolvimento local têm crescido nos últimos tempos. É na perspectiva 
positiva de relações estabelecidas entre diferentes agentes econômicos, políticos e sociais que se entende a importância dos APLs para o desenvolvimento local (LASTRES; CASSIOLATO, 2003). Inclusive, Suzigan et al. (2004) indicam que os APLs são mais voltados ao desenvolvimento, em razão da preconização de instituições de apoio (ex: universidades, escolas técnicas, centros de pesquisa, políticas).

Diante do exposto, mesmo existindo tipologias diferenciadas de aglomerações produtivas, estas, cada uma com as suas peculiaridades, trazem ganhos aos diferentes agentes que mantêm relações interorganizacionais colaborativas, constituindo-se em alternativa viável aos envolvidos. Nessa lógica, os APLs compõem-se num tipo de aglomerado produtivo que facilita e é facilitado por meio da cooperação entre os diferentes agentes, justamente por promover o envolvimento entre agentes econômicos, políticos e sociais. Todavia, apesar das vantagens conferidas pela proximidade geográfica e a especificidade tecnológica (VALE, 2009), em um APL também está presente a complexidade de articulação das ações em conjunto e tomada de decisão coletiva.

Os desafios identificados em arranjos pautados pela cooperação são distintamente visualizados em um APL, são exemplos: a dificuldade na condução e organização de ações de cooperação, que requerem a identificação de alternativas para minimizar os conflitos e estabelecer consenso. Nesta perspectiva, os APLs apresentam diferentes especificidades quanto à sua natureza, formação e desenvolvimento. Porém, existem fatores que são comuns nos APLS como a existência de proximidade geográfica e as questões setoriais (GONÇALVES; LEITE; SILVA, 2012). As diversidades existentes entre os APLs são oriundas das diferentes formas na trajetória de desenvolvimento de cada arranjo e das diferentes formas de organizações que são construídas ao longo do tempo (LASTRES et al. 2014).

Essa forma de entender os arranjos e sistemas locais de produção permite verificar que a existência de um compartilhamento por parte dos agentes do conhecimento tácito (localizado) e também do conhecimento codificado. A interação e o compartilhamento do conhecimento passam a ser fonte geradora de vantagens competitivas e a inovação, fonte central dos processos de competitividade (LUNDVALL, 1988). 
$\mathrm{Na}$ concepção de arranjos e sistemas locais de produção, o processo inovativo é caracterizado como fundado no aprendizado interativo e localizado, que surge das capacitações e dos conhecimentos tácitos e codificados que permite o desenvolvimento de uma dada tecnologia (LUNDVALL, 1988). O autor ressalta que é necessário entender a natureza e a dinâmica do aprendizado. A interação entre usuário-produtor no desenvolvimento de dada tecnologia significa que os processos de aprendizagem resultantes são interativos e, para isso, é necessário confiança e envolvem contextos culturais que vão além das relações contratuais do mercado. Para o autor, é nesse ponto que as instituições de determinado arranjo e sistema produtivo local se tornam importantes para o estabelecimento das regras do jogo, política ou culturalmente estabelecidas. O quadro institucional, portanto, é muito amplo e tem poderoso impacto na organização interna das firmas de um sistema produtivo local.

Diante do exposto, mesmo existindo tipologias diferenciadas de aglomerações produtivas, estas, cada uma com as suas peculiaridades, trazem ganhos aos diferentes agentes que mantêm relações inter-organizacionais colaborativas, constituindo-se em alternativa viável aos envolvidos. Nessa lógica, os APLs compõem-se num tipo de aglomerado produtivo que facilita e é facilitado por meio da cooperação entre os diferentes agentes, justamente por promover o envolvimento entre agentes econômicos, políticos e sociais. Assim, a união das empresas em APL pode proporcionar vantagens como: conhecimentos e tecnologia específicos, mobilidade de conhecimento, identidade tecnológica comum, estratégia coletiva específica, efeitos de aprendizagem traduzidos em capacitação e em inovação, mão de obra adaptada e adequada às necessidades específicas do APL, clientes específicos claramente definidos.

Nesse contexto, a governança surge como um mecanismo essencial para a perenidade do APL. A forma como os atores participantes do APL selecionam, decidem e executam as suas ações coletivas tem influência na cooperação e no desenvolvimento do APL, o que justifica o estabelecimento de mecanismos de governança com vistas a nortear as ações coletivas e proteger os participantes de ações oportunistas (OLIVEIRA; DAMIANI; 2014).

A criação e operacionalização de um mecanismo de governança passa pelo mapeamento das empresas inseridas no APL, identificação dos fatores característicos do APL, e pela definição 
da configuração de governança a ser adotada. O estabelecimento desse mecanismo de governança busca promover o alcance de benefícios oriundos da concentração setorial e territorial, do papel desenvolvido pelas entidades e das formas de relacionamento que favoreçam o desenvolvimento, proporcionando melhor desempenho por meio da realização de ações propositais.

É crescente o interesse dos pesquisadores em compreender como se configura e se desenvolve a governança de um APL (CARIO; NICOLAU, 2012; ALVES et al., 2012; AZEVEDO FILHO; RIBEIRO, 2011). Esses autores concluíram que a governança proporciona maior efetividade no desenvolvimento de ações de cooperação, bem como promove a criação de uma estrutura de coordenação e gestão com vistas a orientar a tomada de decisão. Essa estrutura, quando bem gerida, propicia o ambiente adequado para o estabelecimento de um alto nível de cooperação o que potencializa o acesso a novos recursos e consequentemente oportuniza melhores resultados. Neste sentido, Dias (2013) complementa informando que a inexistência de mecanismos de governança afeta negativamente o desenvolvimento e competitividade do APL. Pois, são inexistentes os regulamentos, normas e contratos formais e informais.

De acordo com Azevedo Filho e Ribeiro (2011), a governança ou a coordenação das ações é necessária para o atingimento dos objetivos do APL. Cançado, Tavares e Dallabrida (2013) sugerem analisar a governança do APL a partir de duas dimensões: estrutural e processual. A dimensão estrutural se ocupa em identificar os atores e suas atividades. Essa dimensão é denominada, por Tavares (2011), de representatividade e contempla a identificação dos atores a partir das seguintes categorias: empresas, fornecedores, instituições de ensino e pesquisa, instituições financeiras, organizações de apoio, organizações de negócio e poder público. Além disso, cada ator do APL pode ser analisado com base nos critérios porte, natureza, finalidade, classificação e tipo de atividade (TAVARES, 2011; AZEVEDO FILHO; RIBEIRO, 2011; CARIO; NICOLAU, 2012).

No que se refere à dimensão processual, esta investiga como as ações conjuntas são planejadas e executadas pelos atores. Essa última dimensão objetiva compreender o mecanismo de governança implantado pelo APL. Possíveis critérios para compreender e analisar 
as ações desenvolvidas em conjunto são: mecanismos utilizados, sistemática de tomada decisão, participação efetiva dos membros, abrangência, frequência, acesso novas oportunidades, recursos compartilhados e aprendizagem gerada (CAMPOS; TRINTIN; VIDIGAL, 2009; SANTOS; CÂNDIDO, 2013; ZAMBRANA; TEIXEIRA, 2013; AZEVEDO FILHO; RIBEIRO, 2003).

Além das dimensões apresentadas, outros autores apresentam derivações à análise de relacionamentos inter-organizacionais. No entanto, entende-se que as apresentadas acima estão alinhadas com os pressupostos básicos de cooperação e compatíveis com a especificidades de um APL.

\section{Metodologia}

Essa pesquisa, de acordo com a literatura, caracteriza-se como um estudo de caso único de natureza descritiva e exploratória. Segundo Yin (2001), a essência de um estudo de caso é que tenta esclarecer uma decisão ou um conjunto de decisões; motivo pelo qual foram tomadas, implementadas e com as quais se obteve os resultados. Segundo autor, o estudo de caso pode ser tratado como importante estratégia metodológica para a pesquisa, pois permite ao investigador um aprofundamento em relação ao fenômeno estudado, revelando nuances difíceis de serem identificadas.

A abordagem da pesquisa é de natureza qualitativa, pois possui o objetivo de explicar o porquê das coisas, exprimindo o que convém ser feito sem quantificar os valores nem se submeter à prova de fatos, já que os dados analisados não são métricos. Para Minayo (2001), a pesquisa qualitativa trabalha com o universo de significados, motivos, aspirações, crenças, valores e atitudes. Conforme o autor, a pesquisa qualitativa verifica uma relação dinâmica entre o mundo real e o sujeito, isto é, um vínculo indissociável entre o mundo objetivo e a subjetividade do sujeito que não pode ser traduzido em números. Este tipo de pesquisa se preocupa em analisar o mundo empírico em seu ambiente natural, valorizando o contato direto entre o pesquisador e a situação a ser estudada, podendo ser conduzida por diferentes caminhos (GODOY, 1995). As pesquisas descritivas realizam o estudo, a análise, o registro e a 
interpretação dos fatos sem a interferência do pesquisador (BARROS; LEHFELD, 2007).

A pesquisa é de caráter exploratório e de natureza descritiva. O objetivo para este estudo, da pesquisa exploratória, foi de fazer uma busca em um problema ou fenômeno para que se possa compreendê-lo de forma mais clara.

Para tanto, foram realizadas entrevistas com sete empresas que foram cadastradas e reconhecidas pelo Governo do Estado do Rio Grande do Sul, via Agência Gaúcha de Desenvolvimento e Promoção do Investimento (AGDI), em 2017, como um APL de TI da Região do Vale do Rio Pardo. O total das empresas cadastradas no documento assinado pelo Governo do Estado do Rio Grande do Sul, constam 26 empresas, localizadas na Região do Vale do Rio Pardo. O recorte metodológico das sete empresas entrevistadas foi realizado observando que essas empresas fossem representativas no mercado de atuação regional. As entrevistas foram realizadas com diretores e proprietários das empresas. Os contatos iniciais para agendamento foram realizados por telefone e as entrevistas foram feitas de forma presencial. Para preservar o nome das empresas e os respondentes, adotou-se a seguinte denominação (Tabela 1):

Tabela 1 - Caracterização das Empresas do APL de TI

\begin{tabular}{lccll}
\hline Empresa & $\begin{array}{c}\text { Ano de } \\
\text { Fundação }\end{array}$ & $\begin{array}{c}\text { Identificação do } \\
\text { Entrevistado }\end{array}$ & Gênero & $\begin{array}{c}\text { Cargo } \\
\text { Ocupado }\end{array}$ \\
\hline Empresa 1 & 2016 & E1 & Feminino & Sócia/Diretora \\
Empresa 2 & 2008 & E2 & Masculino & Sócio/Proprietário \\
Empresa 3 & 2009 & E3 & Masculino & Diretor Executivo \\
Empresa 4 & 2004 & E4 & Masculino & Diretor Fundador \\
Empresa 5 & 2003 & E5 & Masculino & Diretor Executivo \\
Empresa 6 & 1999 & E6 & Masculino & Diretor \\
Empresa 7 & 1999 & E7 & Feminino & Supervisora \\
\hline
\end{tabular}

Fonte: Elaborada pelos autores.

Para o levantamento das informações, foi utilizado um roteiro semiestruturado, com questões abertas, elaborado a partir dos temas centrais que nortearam o propósito do estudo e foram construídos com base no referencial teórico sobre Arranjo Produtivos Locais e aglomerações geográficas.

As principais informações que foram investigadas via realização das entrevistas foram COLóQUIO - Revista do Desenvolvimento Regional - Faccat - Taquara/RS - v. 16, n. 1, jan./jun. 2019 
elaboradas a partir de quatro temas centrais, apresentados a seguir:

- Dados de identificação das empresas: razão social, endereço, origem do capital, responsável pelas informações, dentre outras.

- Características dos produtos/serviços: tipos de produtos/serviços, vantagens e desvantagens locacionais, fatores determinantes para a capacidade competitiva.

- Introdução de inovações e fontes de aprendizagem tecnológica: principais inovações adotadas, principais fontes de informações, forma de incorporação de novas tecnologias, qualificação dos funcionários.

- Formas de cooperação e interação entre os agentes: evolução das relações de cooperação da empresa com os demais atores, formas de intercâmbio com universidades e centros de pesquisa, interação com associações e sindicatos.

As informações coletadas nas entrevistas foram analisadas de forma descritiva e qualitativa. Utilizou-se a análise textual mediante o Software Voyant Tools para identificar as palavras mais utilizadas (nuvem de palavras) em cada tema investigado e também para identificar os termos mais recorrentes nas respostas dos entrevistados. A descrição dos resultados está apresentada juntamente com a utilização de tabelas e figuras, além da devida triangulação com o referencial teórico.

\section{Análise dos resultados}

Essa seção apresenta a análise dos principais resultados obtidos na pesquisa junto às empresas que participam do APL da TI na Região do Vale do Rio Pardo (RS). Inicialmente, no item 4.1, apresenta-se uma contextualização do APL de TI e a caracterização das empresas que foram objeto da pesquisa empírica. Nos itens seguintes, 4.2; 4.3 e 4.4, são analisados e discutidos os principais produtos/serviços das empresas, a introdução de inovações e fontes de aprendizagem tecnológica e as formas de cooperação e interação entre os agentes do APL, respectivamente. 


\subsection{Contextualização do APL e caracterização das empresas}

O APL de TI da Região do Vale do Rio Pardo (RS) é composto, na sua grande maioria, por mico e pequenas empresas (MPE). A Região do Vale do Rio Pardo é considerada uma das mais importantes do Rio Grande do Sul com uma população de mais de 450 mil habitantes (GUIA SOCIOECONÔMICO DO VALE DO RIO PARDO E CENTRO-SERRA, 2018) destacando-se Santa Cruz do Sul (127.429) e Venâncio Aires (70.481).

Conforme descrito na metodologia, o APL de TI é composto, tomando como base o documento do governo do estado, assinado em 2017, onde constam 26 empresas de TI, localizadas na Região do Vale do Rio Pardo, objeto da pesquisa. Além das empresas produtoras de produtos e/ou serviços, no APL de TI destaca-se outros atores importantes como a Universidade de Santa Cruz do Sul (UNISC), a Associação das Empresas de Tecnologia da Informação dos Vales do Rio Pardo e Taquari (ATIVALES), governo municipal e governo estadual. Esses atores são importantes para o desenvolvimento do APL pois agregam conhecimento, interação e ações de fomento junto às empresas. Conforme Lundvall (1988), o desenho institucional existente, ou seja, os atores que atuam direta ou indiretamente, possuem papel determinante na trajetória de desenvolvimento do APL.

Fizeram parte do estudo, sete empresas do ramo de tecnologia da informação do Vale do Rio Pardo, das quais apenas uma possui menos de cinco anos de existência (E1), duas com até dez anos (E2, E3) e, quatro delas com mais de dez anos de mercado (E4, E5, E6 e E7). Os cargos que ocupam, $72 \%$ são de diretoria (E3, E4, E5 e E6), um deles é proprietário (14\% - E2) e o outro supervisor (14\% - E7). As empresas entrevistadas são todas caracterizadas como micro e pequenas. Ressalta-se, neste sentido, que estudos recentes demonstram que as MPE apenas mais recentemente começaram a realizar maiores investimentos em TI e usufruir de parte de seus benefícios (PALVIA; PALVIA, 1999; LUNARDI; DOLCl; MAÇADA, 2010; NGUYEN; NEWBY; MACAULAY, 2015). Além disso, investir em TI tornou-se uma obrigação para muitas 
organizações, seja para acompanhar o que a concorrência tem adotado ou atender às exigências de fornecedores, clientes ou governo (LUNARDI; DOLCI; MAÇADA, 2010).

\subsection{Características dos produtos/serviços}

Quanto aos produtos e/ou serviços produzidos pelas empresas, buscou-se investigar os tipos de produtos/serviços das empresas, as vantagens locacionais e fatores determinantes para a capacidade competitiva das empresas do APL de TI da Região do Vale do Rio Pardo/RS (Tabela 2).

Em relação aos produtos ofertados pelas empresas, foi identificado principalmente o desenvolvimento de softwares e sistemas (E3, E4, E5, E6 e E7), consultoria em TI (E1) e infraestrutura de TI (E2). Apesar de concorrerem no segmento de tecnologia, não chegam a ser diretamente rivais em decorrência de nichos e peculiaridades distintas em produtos e serviços. Neste sentido, as especificidades de cada empresa, dada a natureza de sua trajetória de desenvolvimento, são características que ocorrem nos diferentes APLs (LASTRES et al. 2014). As especificidades podem ser analisadas como fatores positivos na geração e difusão do conhecimento entre as empresas.

Quanto às vantagens locacionais proporcionadas pela proximidade do APL para a competitividade da empresa, a maior parte dos entrevistados destaca a qualificação profissional que o APL proporciona ao agregar empresas do mesmo segmento (E1, E2, E3, E6), além de projetos conjuntos (E5, E7). Além disso, destaca-se que a proximidade geográfica propicia o surgimento de parcerias, de cooperação entre as empresas, como troca de experiências. A troca de experiências entre as empresas representa um ativo intangível muito importante para a dinamização do desenvolvimento do APL, que está relacionado ao conhecimento tácito que vai sendo construído ao longo do tempo entre os agentes (LUNDVALL, 1988).

No tocante a proximidade entre as empresas concorrentes para geração de maior eficiência competitiva, todas responderam que o APL de alguma forma promove algum tipo de cooperação entre empresas, seja na parceria entre empresas (E1, E2), benchmarking (E3, E5), aprendizagem (E4) e/ou novas oportunidades de negócios por meio da cooperação empresarial 
(E7). Esses fatores apontados nas entrevistas como geradores de competitividade refletem as principais características dos APLs apontados na literatura (LASTRES; CASSIOLATO, 2003; GONÇALVES; LEITE; SILVA, 2012; LUNDVALL, 1988).

\section{Tabela 2 - Produtos/Serviços, Vantagens Locacionais e fatores de competitividade}

\begin{tabular}{|c|c|c|c|}
\hline Empresa & Produtos & Vantagens & Fatores de Competitividade \\
\hline E1 & $\begin{array}{l}\text { - Consultoria em } \mathrm{TI} \\
\text { (projetos, sistemas, } \\
\text { suporte) }\end{array}$ & $\begin{array}{l}\text { - Oportunidades de acesso } \\
\text { a treinamentos e eventos }\end{array}$ & $\begin{array}{l}\text { - Parcerias entre empresas em alguns } \\
\text { casos }\end{array}$ \\
\hline E2 & $\begin{array}{l}\text { - Infraestrutura de TI } \\
\text { (servidores, suporte } \\
\text { técnico, cabeamento) }\end{array}$ & $\begin{array}{l}\text { - Qualificação das } \\
\text { empresas } \\
\text { - Inovação } \\
\text { - Parcerias }\end{array}$ & $\begin{array}{l}\text { - Parcerias para qualificação e } \\
\text { captação de clientes }\end{array}$ \\
\hline E3 & $\begin{array}{l}\text { - Software para gestão de } \\
\text { cervejarias }\end{array}$ & $\begin{array}{l}\text { - Troca de experiências } \\
\text { - Cursos, palestras } \\
\text { - Missões conjuntas }\end{array}$ & - Benchmarking entre as empresas \\
\hline E4 & - Software sob demanda & $\begin{array}{l}\text { - Oportunidade de } \\
\text { negócios não atendidas } \\
\text { pelos parceiros } \\
\text { - Qualificação na área de TI }\end{array}$ & $\begin{array}{l}\text { - Aprendizagem } \\
\text { - Cursos de gestão das empresas a } \\
\text { partir das carências comuns }\end{array}$ \\
\hline E5 & $\begin{array}{l}\text { - Software ERP para mídia } \\
\text { exterior e varejo }\end{array}$ & $\begin{array}{l}\text { - Projeto de melhoria } \\
\text { comercial das empresas }\end{array}$ & $\begin{array}{l}\text { - Identificação de pontos convergentes } \\
\text { das empresas } \\
\text { - Melhorias aplicadas com resultados } \\
\text { (Benchmarking) }\end{array}$ \\
\hline E6 & $\begin{array}{l}\text { - Sistemas de gestão para } \\
\text { empresas }\end{array}$ & $\begin{array}{l}\text { - Cursos e eventos } \\
\text { compartilhados na região }\end{array}$ & - Aproximação das empresas de TI \\
\hline E7 & $\begin{array}{l}\text { - Sistemas de gestão para } \\
\text { governança corporativa }\end{array}$ & $\begin{array}{l}\text { - Projetos em TI } \\
\text { compartilhados } \\
\text { - Obtenção de novos } \\
\text { clientes }\end{array}$ & $\begin{array}{l}\text { - Atuações distintas das empresas } \\
\text { proporcionam oportunidades e } \\
\text { negócios a todos (cooperação) }\end{array}$ \\
\hline
\end{tabular}

Fonte: Elaborada pelos autores.

4.3 Introdução de inovações e fontes de aprendizagem tecnológica

Nessa seção serão abordados os resultados obtidos com às inovações adotadas, principais fontes de informações e estratégias usadas, além das formas de incorporação de novas tecnologias nas empresas. 
Com relação as principais ações adotadas pelas empresas nos últimos anos, anos, destacam a inserção de alguma inovação ou aprendizagem. Com destaque para produtos tecnológicos (E1, E2), gestão (E3, E4, E7) e processos internos (E5, E6). Verifica-se que são realizados investimentos na qualificação do seu quadro de funcionários e em ações que são realizadas de forma conjunta com outras empresas do APL. Isso remete aos estudos científicos, já realizados sobre APLs, que a qualificação da mão-de-obra dentro de um determinado espaço geográfico, é fruto das interações que o aglomerado vai construindo, cujo autor mais conceituado na literatura, Alfred Marshall, no início dos anos de 1920, já indicava esses resultados. Marshall foi o autor clássico da literatura que introduziu o termo como geração de externalidades positivas, para explicar nos seus estudos os benefícios da proximidade geográfica entre empresas e um dos fatores era a existência de mão-de-obra mais qualificada.

Quanto aos tipos de informações e estratégias utilizadas pela empresa para a introdução de inovações, foram destacadas a pesquisa de mercado (E1, E4, E5), desenvolvimento interno e qualificação da equipe (E2, E3, E7). Apenas a Empresa 6 não possui nada estruturado ou sistematizado.

No tocante a incorporação de novas tecnologias nas empresas, todas destacaram alguma ação, por meio de pesquisa e estudos informais de novas tecnologias (E1, E2, E6, E7) ou até mesmo por meio de ações mais formais para incorporação dessas tecnologias (E3, E4, E5). A Tabela 3, apresentada na próxima página, apresenta os resultados obtidos individualmente para cada um dos entrevistados, no que tange às inovações e aprendizagens de tecnologia nas empresas do APL. 
Tabela 3 - Inovações e aprendizagem tecnológica das empresas

\begin{tabular}{|c|c|c|c|}
\hline Empresa & $\begin{array}{l}\text { Inovações e aprendizagem } \\
\text { adotadas na empresa }\end{array}$ & $\begin{array}{l}\text { Tipos de informação/estratégia } \\
\text { para introdução da inovação }\end{array}$ & $\begin{array}{l}\text { Incorporação de novas } \\
\text { tecnologias }\end{array}$ \\
\hline E1 & $\begin{array}{l}\text { - Reposicionamento } \\
\text { - Incorporando novos } \\
\text { produtos e serviços }\end{array}$ & - Pesquisa e análise de mercado & $\begin{array}{l}\text { - Grupos de estudo para } \\
\text { compreender novas } \\
\text { tecnologias e aplicá-las }\end{array}$ \\
\hline E2 & $\begin{array}{l}\text { - Qualificação constante em } \\
\text { novas tecnologias } \\
\text { - Atuação na vanguarda e } \\
\text { tendência tecnológica }\end{array}$ & $\begin{array}{l}\text { - Qualificação e estudo de novas } \\
\text { tecnologias } \\
\text { - Testes de implementação de novas } \\
\text { tecnologias } \\
\text { - Oferta de soluções de novas } \\
\text { tecnologias aos clientes }\end{array}$ & $\begin{array}{l}\text { - Informalmente } \\
\text { - Pesquisas na internet } \\
\text { - Cursos e treinamentos } \\
\text { - Testes }\end{array}$ \\
\hline E3 & $\begin{array}{l}\text { - Fortalecimento do time } \\
\text { - Adoção de ferramentas de } \\
\text { marketing de conteúdo }\end{array}$ & $\begin{array}{l}\text { - Implementação de um período } \\
\text { semanal de inovação para pesquisa } \\
\text { e teste de soluções inovadoras }\end{array}$ & $\begin{array}{l}\text { - Plano de ação para } \\
\text { adoção de soluções } \\
\text { inovadoras (Quem, } \\
\text { quando e custo) }\end{array}$ \\
\hline$\overline{\mathrm{E} 4}$ & $\begin{array}{l}\text { - Qualificação setor comercial } \\
\text { - Qualificação e valorização } \\
\text { dos técnicos em TI } \\
\text { - Produtos direcionados ao } \\
\text { mercado } \\
\text { - Investimento em pesquisa }\end{array}$ & $\begin{array}{l}\text { - Análise de mercado } \\
\text { - Uso do potencial interno para } \\
\text { desenvolvimento tecnológico } \\
\text { - Compartilhamento de decisões e } \\
\text { pesquisa entre a equipe }\end{array}$ & $\begin{array}{l}\text { - Desenvolvimento de } \\
\text { projeto “piloto" para } \\
\text { domínio de novas } \\
\text { tecnologias }\end{array}$ \\
\hline E5 & $\begin{array}{l}\text { - Uso de métodos ágeis } \\
\text { - Automação de processos de } \\
\text { compilação e testes }\end{array}$ & $\begin{array}{l}\text { - Pesquisa e tendência de mercado } \\
\text { - Adequação aos profissionais } \\
\text { disponíveis na região }\end{array}$ & $\begin{array}{l}\text { - De modo agressivo e } \\
\text { constante para se manter } \\
\text { no mercado }\end{array}$ \\
\hline E6 & $\begin{array}{l}\text { - Revisão de processos } \\
\text { internos } \\
\text { - Implementação de } \\
\text { melhorias } \\
\text { - Integração dos produtos } \\
\text { com novas tecnologias de } \\
\text { aplicativos }\end{array}$ & $\begin{array}{l}\text { - Não possuem nada estruturado na } \\
\text { empresa }\end{array}$ & $\begin{array}{l}\text { - Pesquisa } \\
\text { - Testes } \\
\text { - Implementação }\end{array}$ \\
\hline E7 & $\begin{array}{l}\text { - Criação de uma unidade } \\
\text { interna destinada à } \\
\text { inovação e } \\
\text { internacionalização }\end{array}$ & $\begin{array}{l}\text { - Participação em eventos } \\
\text { - Uso da internet para acompanhar } \\
\text { tendências }\end{array}$ & $\begin{array}{l}\text { - Pesquisa de novos } \\
\text { produtos } \\
\text { - Pesquisa de satisfação } \\
\text { com clientes e aceitação } \\
\text { de produtos }\end{array}$ \\
\hline
\end{tabular}

Fonte: Elaborada pelos autores.

A Figura 3 complementa e ilustra os termos mais utilizados pelos entrevistados à cada uma das questões dessa seção por frequência de utilização. As empresas, num contexto 
econômico onde as tecnologias surgem e são introduzidas de maneira cada vez mais rápidas, as empresas buscam informações via pesquisas de mercado, desenvolvimento de novos produtos e adoção de novas tecnologias. De acordo com Tigre (2006), as empresas buscam definir suas estratégias tecnológicas a partir da sua natureza e de sua posição no mercado.

Figura 3 - Nuvem de palavras das inovações e fontes de aprendizagem tecnológica

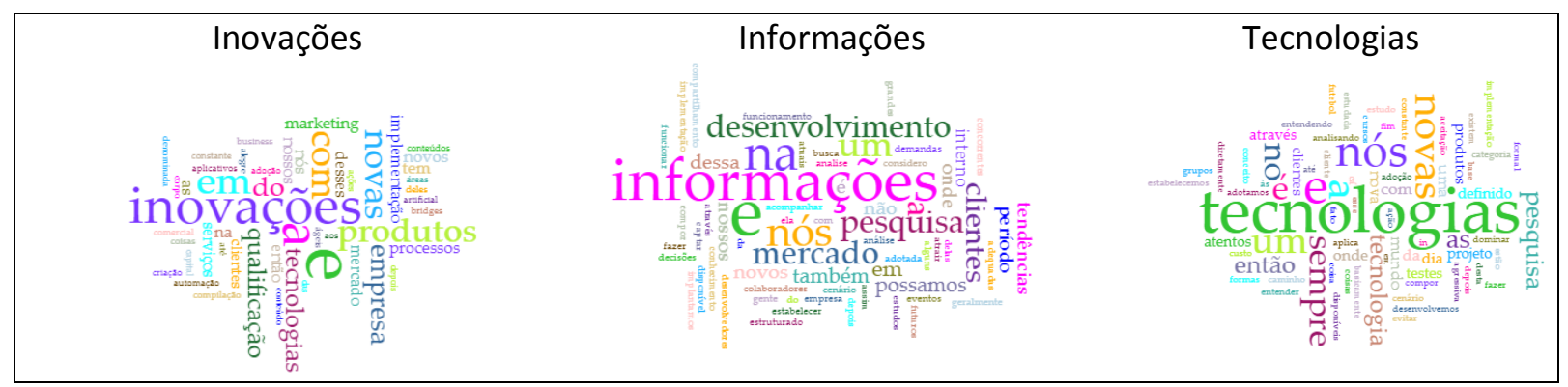

Fonte: Resultados da pesquisa.

A Figura 4 destaca os termos das respostas mais expressivas para cada questão central da presente seção. Sendo que para as principais inovações incorporadas nessas empresas, estão novos produtos e serviços tecnológicos, a gestão da organização e dos seus processos internos.

\section{Figura 4 - Mandala das inovações e fontes de aprendizagem tecnológica}

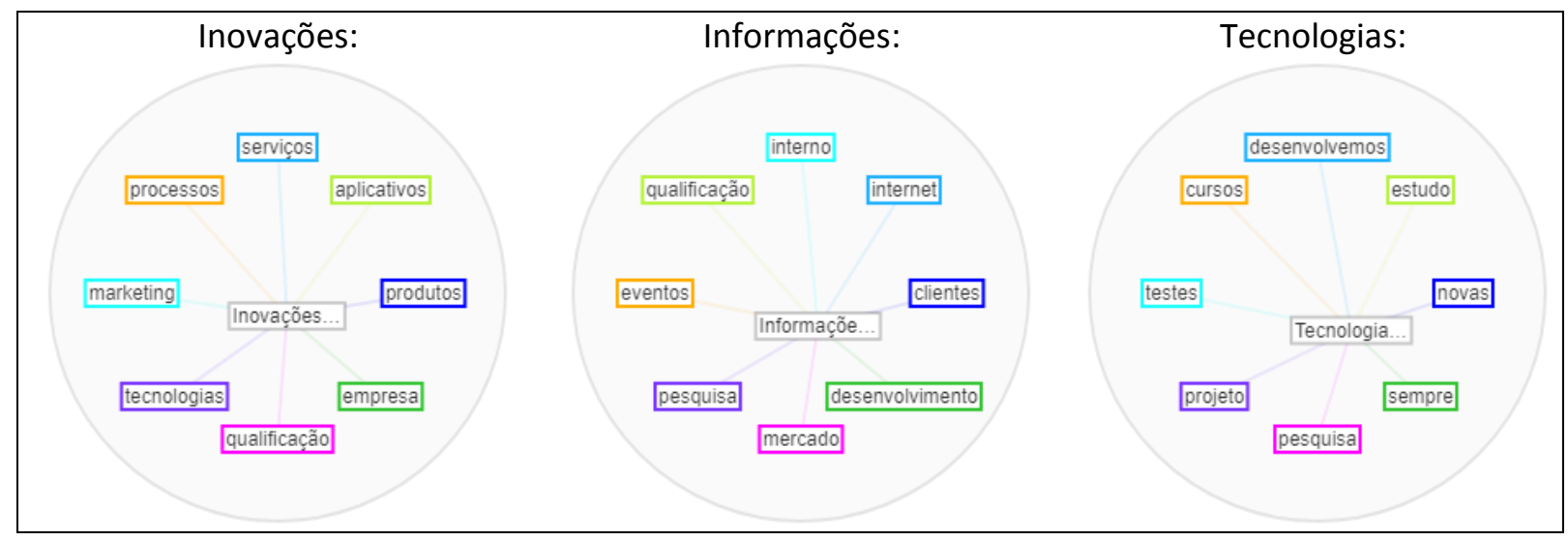

Fonte: Elaborada pelos autores a partir das entrevistas.

Em relação a informação e estratégia usada para introdução dessas inovações no mercado, o destaque foi para pesquisa de mercado e com clientes, desenvolvimento interno e a 
participação em cursos de qualificação e eventos sobre TI. A incorporação dessas tecnologias se dá de modo constante em algumas empresas por meio de projetos, estudos, testes e pesquisa visando a incorporação e desenvolvimento de novas tecnologias.

\subsection{Formas de cooperação e interação entre os agentes}

Essa seção destaca a evolução das relações de cooperação da empresa com os demais atores, formas de interação e de relacionamento com empresas do APL, de atuação com associações, universidade e governo.

As empresas, ao serem entrevistadas sobre como ocorrem às relações de cooperação no APL de TI do Vale do Rio Pardo, responderam que cooperam de diversas formas: por meio de reuniões $(E 3, E 5)$, projetos comuns $(E 4, E 6)$, prestação de serviços (E1, E2) e qualificação profissional (E7). A outra questão identificou se o APL de TI propicia maiores relacionamentos de cooperação ou parceria entre as empresas, como resposta, duas empresas disseram que não existe uma relação direta e formal entre às empresas (E1, E7), uma das empresas destacou que a relação ainda é fraca (E2), já às demais disseram que realizaram alguma integração relacional por meio de atividades comuns, missões conjuntas e associações entre às empresas (E3, E4, E5). Todavia é perceptível que o APL de TI ainda poderá evoluir nas relações formais objetivando maior cooperação entre empresas. Por fim, ao serem questionadas sobre a existência de interação e troca de conhecimento com a universidade, associações de classe ou governo, apenas uma empresa respondeu que não (E5). Todas demais mencionaram ao menos uma interação com algum desses agentes: universidade, associação ou governo (E1, E2, E3, E4, E6, E7), sintetizados na Tabela 4. Isso indica, na pesquisa exploratória, que os atores externos às empresas representam importante papel para a realização de relações de cooperação. Que mesmo não existindo, até o momento, uma governança formal no APL, os mecanismos de cooperação estão sendo realizados entre os agentes, como também destacado em outros estudos científicos (SANTOS; CANDIDO, 2013; TAVARES, 2011). 
Tabela 4 - Relações de cooperação entre os agentes do APL de TI

\begin{tabular}{|c|c|c|c|}
\hline Empresa & $\begin{array}{l}\text { Como ocorrem às relações de } \\
\text { cooperação }\end{array}$ & $\begin{array}{l}\text { Como o APL proporciona } \\
\text { relacionamento }\end{array}$ & $\begin{array}{c}\text { Interação com universidades, } \\
\text { associações, governo }\end{array}$ \\
\hline E1 & $\begin{array}{l}\text { - Prestação de serviço } \\
\text { - Fornecedor } \\
\text { - Trabalhos conjuntos }\end{array}$ & - Não foi identificado & $\begin{array}{l}\text { - Interação com associação de } \\
\text { classe }\end{array}$ \\
\hline E2 & $\begin{array}{l}\text { - Entre empresas com know- } \\
\text { how insuficiente } \\
\text { - Para complementação de } \\
\text { serviços } \\
\text { - Apoio de experiência }\end{array}$ & $\begin{array}{l}\text { - Atualmente a relação é } \\
\text { pouca } \\
\text { - Depende de longo prazo } \\
\text { - Necessário eventos e } \\
\text { interação }\end{array}$ & $\begin{array}{l}\text { - Nas associações de classe por } \\
\text { meio de eventos }\end{array}$ \\
\hline E3 & $\begin{array}{l}\text { - Reuniões eventuais para troca } \\
\text { de experiências entre } \\
\text { empresas }\end{array}$ & $\begin{array}{l}\text { - Por meio de integração } \\
\text { de soluções conjuntas }\end{array}$ & $\begin{array}{l}\text { - Em associações e universidades } \\
\text { com eventos, cursos, palestras }\end{array}$ \\
\hline E4 & $\begin{array}{l}\text { - Por meio de incubadora de TI } \\
\text { - Eventos técnicos, acadêmicos } \\
\text { - Parcerias em projetos }\end{array}$ & $\begin{array}{l}\text { - Por meio de atividades } \\
\text { comuns e diretas entre } \\
\text { empresas }\end{array}$ & $\begin{array}{l}\text { - Interação constante entre } \\
\text { governo, universidade e empresa } \\
\text { - Órgão de classe } \\
\text { - Conselho municipal } \\
\text { - Entidades empresariais }\end{array}$ \\
\hline E5 & $\begin{array}{l}\text { - Reuniões } \\
\text { - Contato em grupo whatsapp }\end{array}$ & - Missões conjuntas & - Não \\
\hline$\overline{E 6}$ & $\begin{array}{l}\text { - Indicações } \\
\text { - Projetos comuns } \\
\text { - Troca de ideias } \\
\end{array}$ & $\begin{array}{l}\text { - A associação sempre } \\
\text { fomentou e executou o } \\
\text { relacionamento }\end{array}$ & $\begin{array}{l}\text { - Por meio de uma nova pós- } \\
\text { graduação que permitirá a } \\
\text { participação da empresa }\end{array}$ \\
\hline E7 & $\begin{array}{l}\text { - Qualificações da equipe } \\
\text { comercial em cursos }\end{array}$ & $\begin{array}{l}\text { - Ainda não houve } \\
\text { experiências de atuação } \\
\text { conjuntas/empresas } \\
\text { - Com o tempo poderá } \\
\text { haver maior } \\
\text { aproximação na relação }\end{array}$ & $\begin{array}{l}\text { - Pouca expressiva na região } \\
\text { - Interação maior ocorre com a } \\
\text { universidade na semana } \\
\text { acadêmica }\end{array}$ \\
\hline
\end{tabular}

Fonte: Elaborada pelos autores. 
A Figura 5 ilustra o emprego dos principais termos empregados pelas empresas em relação à essas questões.

Figura 5 - Nuvem de palavras das relações de cooperação entre os agentes do APL

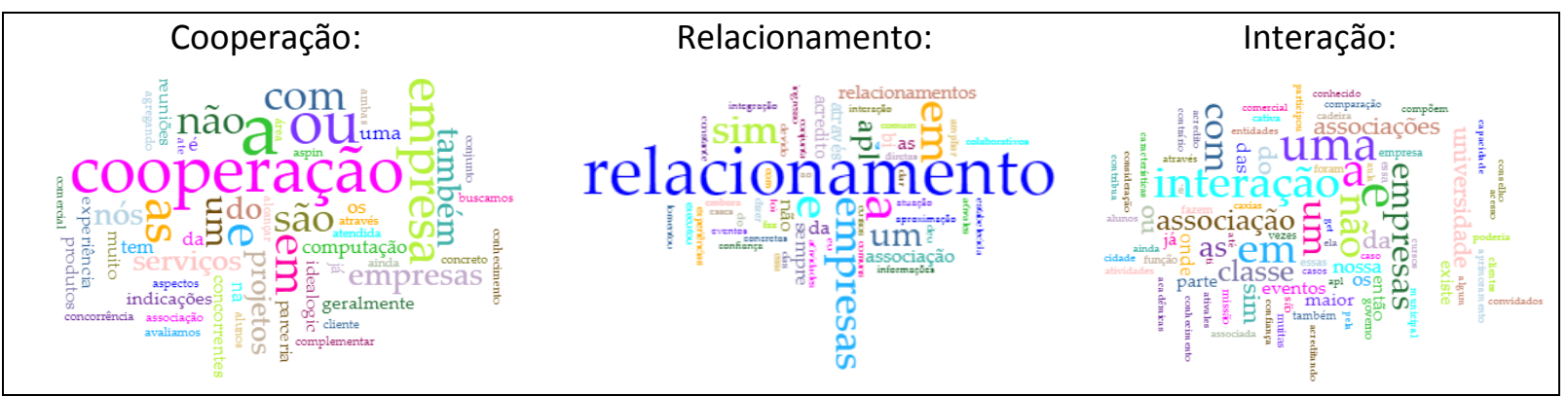

Fonte: Elaborado pelos autores

Com o propósito de identificar as principais palavras-chave para cada questão, utilizouse a análise textual por software permitiu constatar que a cooperação entre empresas se dá mediante projetos, parcerias, serviços, indicações, troca de experiências em computação e

Figura 6 - Mandala das relações de cooperação entre os agentes do APL de TI

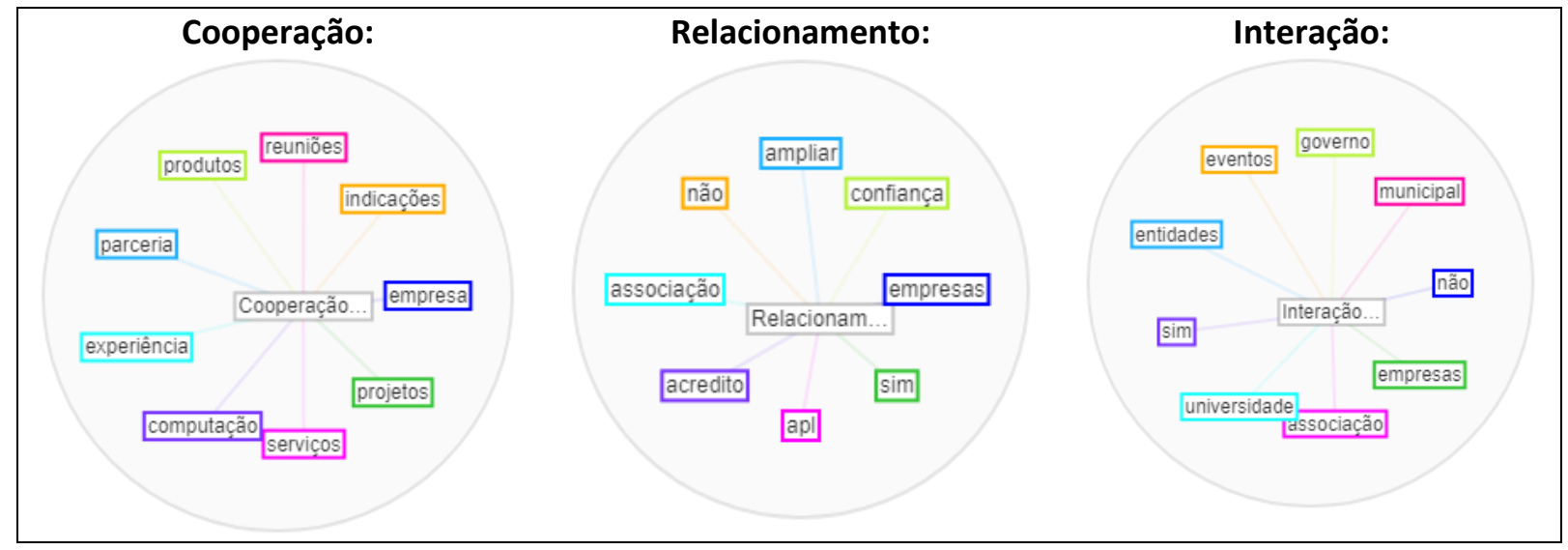

Fonte: Elaborado pelos autores.

Observa-se que as relações de cooperação, na sua maioria não são formalizadas, ocorrem em função da proximidade geográfica do APL. Esse resultado está totalmente alinhado com os diversos estudos acadêmicos já realizados sobre o tema. Estudos que indicam que as 
interações, as relações de cooperação podem ocorrer tanto de maneira formal como informal, dado que os APLs são aglomerações geográficas com diferentes especificidades, que decorrem de cada trajetória de desenvolvimento entre os atores dos aglomerados. E a maioria dos estudos já realizados demonstram que os APLs não apresentam uma governança estruturada/realizam ações de cooperação que dinamizam o desenvolvimento econômico de determinado espaço local (RIBEIRO et. al, 2013; ALBUQUERQUE, NÓBREGA, 2013).

\section{Considerações finais}

O objetivo do trabalho de verificar se as questões relativas à proximidade geográfica do aglomerado produtivo permitem que as relações de cooperação ocorram com maior intensidade e sejam fatores de competitividade e inovação de um arranjo produtivo local foi atingido. Para tanto, foi realizada uma pesquisa qualitativa de caráter exploratório e de natureza descritiva com o APL de TI da Região do Vale do Rio Pardo. Das 26 empresas, 7 foram escolhidas para participar do estudo devido a sua representatividade no mercado de atuação regional.

O APL de TI da Região do Vale do Rio Pardo é caracterizado por micro e pequenas empresas (MPEs). As MPEs desempenham um papel fundamental na revitalização e desenvolvimento da economia nacional em muitos países, fornecendo vários bens e serviços, formando uma estrutura de divisão do trabalho adequada e melhorando economias regionais e comunidades (BERISHA-NAMANI, 2009). Fundamentais para a renovação do sistema econômico, as MPEs abrem caminho a novos modelos de ideias e negócios, removem produtos e processos ineficientes, que, por sua vez, levam ao desenvolvimento econômico (SCHUMPETER, 1982). Assim, empresas menores são necessárias para equilibrar o mercado por meio do aumento da concorrência e redução de ameaças de práticas monopolistas. Portanto, não é surpreendente o apoio que tais empresas recebem em diversas regiões, como na Comunidade Europeia, em que apoiar as pequenas empresas é uma das prioridades para o crescimento econômico, criação de emprego e coesão econômica e social. No Brasil, o papel de 
destaque das MPEs na economia ganhou ainda mais força com a entrada em vigor da Lei Geral da Micro e Pequena Empresa, em 2007, e da Lei do Empreendedor Individual, em 2008, leis decisivas para impulsionar o empreendedorismo no Brasil (SEBRAE, 2010).

A partir da análise das informações coletadas, nas empresas entrevistadas, foi possível analisar como as empresas estão entendendo a importância da aproximação geográfica como fator competitivo, ou seja, se o fato de estarem localizadas em um dado espaço local existem vantagens advindas de cooperação e troca de informações que possibilitam a geração de externalidades positivas para o conjunto de empresas. O primeiro resultado relevante da pesquisa foi a identificação de um aglomerado produtivo de micro e pequenas empresas de $\mathrm{TI}$ no Vale do Rio Pardo que interagem entre si de diversas formas e recebe o apoio de diferentes agentes identificados no estudo como a UNISC, o ATIVALES, o governo municipal e o governo estadual. Sotello et al. (2018) apontam que nesse tipo de arranjo, a criação dos relacionamentos que vão além das fronteiras internas propicia o compartilhamento de recursos, ampliam as competências das organizações e criam valor coletivo para o território. Assim, os atores possuem um papel fundamental na manutenção e desenvolvimento do APL agregando conhecimentos e ações para de fomento para as empresas da região. Devido a importância da TI para o contexto atual, esse tipo de iniciativa é muito válido e importante para a região e comunidade como um todo. Novas soluções foram identificadas como fruto dessa interação e proximidade geográfica como desenvolvimento de softwares e sistemas; consultorias em TI e melhoria da infraestrutura de $\mathrm{Tl}$ da região. Foi identificado que mesmo atuando de maneira próxima, as empresas não foram identificadas como rivais, pois atendem nichos e particularidades diferentes ofertando distintos produtos e serviços. Outro resultado que merece destaque, foi que a proximidade das empresas possibilita uma maior qualificação profissional que o APL proporciona, além de propiciar o surgimento de parcerias e cooperação através, por exemplo, de projetos em conjunto. Essa troca de experiências pode ser considerada um ativo intangível do APL.

Como mencionado, a cooperação existe entre as empresas do APL e diferentes atores. Essa cooperação ocorre de diversas formas: meio de reuniões, projetos comuns, prestação de 
serviços, missões conjuntas, associações e qualificação profissional. Em relação à Universidade e ao Governo, a cooperação ocorre em 6 das 7 empresas analisadas sob a forma de troca de conhecimento e desenvolvimento em conjunto. Rocha et al. (2018) alertam que muitas vezes que a cooperação baseada prioritariamente no compartilhamento de informações, podem não se constituir na operacionalização de atividades conjuntas propriamente ditas. Destaca-se que essa interação não é formalizada ainda e não existe um processo sistemático para essas atividades. Assim, como resultado do estudo, também, aponta-se que esse tipo de práticas deve ser considerado e analisado para que o conhecimento gerado nessas interações e cooperações não se perca no meio do processo.

As inovações identificadas no APL analisado, foram focadas em produtos tecnológicos, gestão e processos internos. Essas inovações foram identificadas como oriundas de pesquisas de mercado, desenvolvimento interno e qualificação da equipe. Esses resultados estão em consonância com os estudos de Baldisera, Ceretta e Reis, (2017) que encontraram que os proprietários, clientes e P\&D são as principais fontes de inovação desse tipo de empresa. Práticas formais e informais são utilizadas pelas empresas analisadas relacionada com atividades inovadoras, podendo-se destacar grupos de estudo para compreender as novas tecnologias e aplicá-las; cursos, treinamentos, planos de ação mais agressivos e diferentes tipos de pesquisas de satisfação, aceitação, de mercado e de novos produtos.

\section{Referências}

ALBUQUeRQUE, R. A. de; NÓBREGA, K. C. Arranjo Produtivo Local como Estratégia para o Incremento da Competitividade de Pequenas Empresas do Segmento de Panificação do RN. In: Anais do XXXVII ENANPAD. Rio de Janeiro, 2013.

ALVES, L. da C. et al. Governança em arranjos produtivos locais: um estudo sobre o APL do leite de Sant'ana do Livramento. In: Encontro Nacional de Engenharia de Produção. Anais... Bento Gonçalves, 2012. p. 1-9. 
AZEVEDO FILHO, E. T.; RIBEIRO, A. das C. A governança em aglomerações produtivas: uma análise sobre o setor cerâmico de Campos dos Goytacazes. Revista Brasileira de Gestão e Desenvolvimento Regional,Taubaté, v. 7, n. 1, p. 96-129, jan./abr. 2011.

BALDISERA, H., CERETTA, G. F.; REIS, D. R. Relação entre intraempreendedorismo e inovação: um estudo em empresas participantes do APL de TI do sudoeste do paraná. Gestão \& Regionalidade, v. 33, n. 97, jan./abr. 2017.

BARROS, A. J. S.; LEHFELD, N. A. S. Fundamentos da Metodologia Científica. 3. ed. Pearson Education, 2007.

BERISHA-NAMANI, Mihane. The Role of Information Technology in Small and Medium Sized Enterprises in Kosova. In: Fulbright Academy Conference, 2009.

BRASIL. Ministério do Desenvolvimento, Indústria e Comércio Exterior. Portaria Interministerial no 200, de 02 de agosto de 2004. Institui o Grupo de Trabalho Permanente para Arranjos Produtivos Locais - GTP APL.

CAMPOS, A. C. de; TRINTIN, J. G.; VIDIGAL, V. G. Estrutura de Governança: o caso do arranjo produtivo local (APL) do setor de confecção de Maringá (PR). Textos de Economia. Florianópolis, v. 12, n. 1, p. 134-155, 2009.

CANÇADO, A. C.; TAVARES, B.; DALLABRIDA, V. R. Gestão social e governança territorial: interseções e especificidades teórico-práticas. Revista Brasileira de Gestão e Desenvolvimento Regional, Taubaté, v. 9, n. 3, p. 313-353, set./dez. 2013.

CARIO, S. A. F.; NICOLAU, J. A. Estrutura e padrão de governança em arranjos produtivos locais no Brasil: um estudo empírico. Ensaios FEE, Porto Alegre, v. 33, n. 1, p. 177-206, maio 2012.

CASTRO, M. de; GONÇALVES, S. A. Contexto institucional de referência e governança de redes: estudo em arranjos produtivos locais do estado do Paraná. Revista da Administração Pública, Rio de Janeiro, v. 48, n. 5, p. 1281-1304, set./out. 2014.

COSTA, A. B.; COSTA, B. M. Cooperação e capital social em arranjos produtivos locais. Revista de Desenvolvimento Econômico (RDE), ano IX, n. 15, Salvador, jan. 2007.

DIAS, Robson. Institutions and territorial development: a case study from the productive arrangement of oil and natural gas located in Macae, Brazil. Revista Latinoamericana de Estudios Urbano Regionales (Eure), v. 39, n. 116, p. 141-171, 2013.

GODOY, A.S. Introdução à pesquisa qualitativa e suas possibilidades. RAE - Revista de Administração de Empresas, São Paulo, v. 35, n. 2, p. 57-63, 1995. 
GONÇALVES, A. T. P.; LEITE, M. S. A.; SILVA, R. M. da. Um estudo preliminar sobre as definições e as diferenças dos principais tipos de arranjos empresariais. Revista Produção Online, v. 12, n. 3, p. 827-854, 2012.

GUIA SOCIOECONÔMICO DO VALE DO RIO PARDO E CENTRO-SERRA, 2018. Disponível em: <http://www.gaz.com.br/arquivos_biblioteca/2018/07/04/GUIA_2018_1928918d86a708dd24c b7c977ff84ec7.pdf>. Acesso em: 12 dez. 2017.

LASTRES H. M. M.; CASSIOLATO, J. E. Glossário de arranjos e sistemas produtivos e inovativos locais. 2003. Disponível em: <http://www.ie.ufrj.br/redesist/P4/textos/Glossario.pdf>. Acesso em: 12 dez. 2017.

LASTRES, H. M. M. et al. O apoio ao desenvolvimento regional: a experiência do BNDES e oportunidades para avanços. Revista do BNDES, Rio de Janeiro, n. 42, p. 5-46, dez. 2014.

LUNARDI, G. L.; DOLCI, P. C.; MAÇADA, A. C. G. Adoção de Tecnologia de Informação (TI) e seu Impacto no Desempenho Organizacional: Um Estudo realizado com Micro e Pequenas Empresas. RAUSP. Revista de Administração, São Paulo, v. 45, n. 1, p. 5-17, jan./fev./mar. 2010.

LUNDVALL, Bengt-Åke. Innovation as an interactive process: from user-producer interaction to the national system of innovation. In: DOSI, G. et al. (Eds.). Technical change and economic theory. Londres: Pinter Publishers, p. 349-369, 1988.

MINAYO, Maria Cecília de Souza. Pesquisa Social: teoria, método e criatividade. 18. ed. Petrópolis: Vozes, 2001.

NGUYEN, T. H.; NEWBY, M.; MACAULAY, M. J. Information Technology Adoption in Small Business: Confirmation of a Proposed Framework. Journal of Small Business Management, v. 1, n. 53, p. 207-227, 2015.

OLIVEIRA, J. P. L. de; DAMIANI, J. H. de S. Governance structures in clusters: A case study on software cluster in the state of São Paulo. In: Management of Engineering \& Technology (PICMET), 2014. Portland International Conference on. IEEE, 2014. p. 336-345.

PALVIA, P.; PALVIA, S. An examination of the IT satisfaction of small business users. Information \& Management, Netherlands, v. 5, n. 35, p. 127-137, mar. 1999.

RIBEIRO, K. A. et al. Arranjo produtivo local (APL) como estratégia de potencializar as fronteiras mercadológicas do apicultor no perímetro de irrigação Senador Nilo Coelho em Petrolina - PE. Revista Gestão, Finanças e Contabilidade, v. 3, n. 2, maio/ago. 2013. 
ROCHA, R. O. et al. Análise do uso de redes sociais digitais para promoção de cooperação e aprendizado no arranjo produtivo local de tecnologia da informação de Aracaju/SE. Ideias \& Inovação, v. 4, n.3, p. 35-46, 2018.

SANTOS, A. E. A. dos; CÂNDIDO, G. A. Estruturas de governança em arranjos produtivos locais: uma aplicação no arranjo calçadista no município de Campina Grande-PB. In: Encontro da ANPAD, 37, 2013, Rio de Janeiro, RJ. Anais... Rio de Janeiro, p. 1-16, 2013.

SCHUMPETER, Joseph Alois. Teoria do desenvolvimento econômico. São Paulo: Abril Cultural, 1982.

SEBRAE. 2010. Disponível em: <http://www.sebrae.com.br/customizado/estudos-e-pesquisas/ temas-estrategicos/empreendedorismo/livro_gem_2010.pdf>. Acesso em: 28 dez. 2017.

SOTELLO, F. et al. Fatores que influenciam a inovação aberta: análise do APL Iguassu-IT de tecnologia da informação do oeste do Paraná. Revista Brasileira de Gestão e Inovação, v. 6, n. 1, 2018.

SUZIGAN, W. et al. Clusters ou Sistemas Locais de Produção: mapeamento, tipologia e sugestões de políticas. Revista de Economia Política, v. 24, n. 2, out./dez. 2004.

TAVARES, Hermes Magalhães. Estratégias de desenvolvimento regional. Da grande indústria ao Arranjo Produtivo Local? Revista Brasileira de Gestão e Desenvolvimento Regional, Taubaté, v. 7, n. 1, p. 50-68, jan./abr. 2011.

TIGRE, Paulo Bastos. Gestão da inovação: a economia da tecnologia no Brasil. Rio de Janeiro: Campus, 2006.

VALE, Mário. Conhecimento Inovação e Território. Finisterra, v. XLIV, n. 88, p. 9-22, 2009.

YIN, R. K. Estudo de Caso: planejamento e métodos. Porto Alegre: Bookman, 2001.

ZAMBRANA, A. de A.; TEIXEIRA, R. M. Governança e cooperação em arranjos produtivos locais: um estudo de múltiplos casos em Sergipe. Revista de Gestão USP, São Paulo, v. 20, n. 1, p. 21-42, jan./mar. 2013. 